\title{
Determination of Morphine and Codeine in Human Urine by Gas Chromatography-Mass Spectrometry
}

\author{
Xiaoqian Zhang, ${ }^{1}$ Mengchun Chen, ${ }^{1}$ Gaozhong Cao, ${ }^{2}$ and Guoxin $\mathrm{Hu}^{1}$ \\ ${ }^{1}$ School of Pharmacy of Wenzhou Medical University, Wenzhou 325035, China \\ ${ }^{2}$ The First Affiliated Hospital of Wenzhou Medical University, Wenzhou 325000, China \\ Correspondence should be addressed to Guoxin Hu; wzhhgx@yahoo.com.cn
}

Received 30 May 2013; Revised 22 August 2013; Accepted 28 August 2013

Academic Editor: Jianxiu Du

Copyright (C) 2013 Xiaoqian Zhang et al. This is an open access article distributed under the Creative Commons Attribution License, which permits unrestricted use, distribution, and reproduction in any medium, provided the original work is properly cited.

\begin{abstract}
A sensitive and selective gas chromatography-mass spectrometry (GC-MS) method was developed and validated for the determination of morphine and codeine in human urine. The GC-MS conditions were developed. The analysis was carried out on a HP-1MS column $(30 \mathrm{~m} \times 0.25 \mathrm{~mm}, 0.25 \mu \mathrm{m})$ with temperature programming, and Helium was used as the carrier gas with a flow rate of $1.0 \mathrm{~mL} / \mathrm{min}$. Selected ion monitoring (SIM) mode was used to quantify morphine and codeine. The derivation solvent, temperature, and time were optimized. A mixed solvent of propionic anhydride and pyridine $(5: 2)$ was finally used for the derivation at $80^{\circ} \mathrm{C}$ for $3 \mathrm{~min}$. Linear calibration curves were obtained in the concentration range of $25-2000.0 \mathrm{ng} / \mathrm{mL}$, with a lower limit of quantification of $25 \mathrm{ng} / \mathrm{mL}$. The intra- and interday precision (RSD) values were below 13\%, and the accuracy was in the range $87.2-108.5 \%$. This developed method was successfully used for the determination of morphine and codeine in human urine for forensic identification study.
\end{abstract}

\section{Introduction}

Morphine and codeine are naturally occurring alkaloids in opioid plants, have long been used as a drug, and are also abused. While the presence of illicit drugs or their metabolites in urine is an evidence of intake, their concentrations in blood are expected to correlate with their effects on the central nervous system [1]. Morphine is a powerful narcotic analgesic and highly addictive. Codeine is a potent $\mu$-opioid receptor agonist which is used for the treatment of adult cough. Simultaneously, there have been athletes in sports competitions who use a larger dose in order to improve performance. This practice is contrary to the principle of fair competition and also harmful to the health of the athletes' body. Heroin as one of the most widely abused drug, rapidly metabolized to 6-monoacetylmorphine (6-MAM) once inside the human body. This specific heroin metabolite 6-MAM is detected at a higher concentration usually within 2 to 4 hours, and after six hours, has not been detected in the urine. The absence of 6-MAM in urine, however, morphine is both a wellknown pharmaceutical agent and an important metabolite of codeine and heroin which have relatively long a detection time. Morphine and codeine analysis of urine is used in forensic toxicology to study drug addiction.

There are numerous papers published about the simultaneous determination of Morphine and Codeine in human fluids, including the micellar electrokinetic chromatography (MEKC) method [2], disposable pipette extraction (DPX) method [3], high performance liquid chromatography method [4], liquid chromatography-mass spectrometry [5], and liquid chromatography/triple quadrupole tandem mass spectrometry (LC/MS/MS) method [6-8]. Several gas chromatography-mass spectrometry (GC-MS) methods have been developed for the analysis of codeine, morphine, or other opiates. Much attention has been directed to the confirmation of morphine and codeine in urine by GCMS [9]. A few methods have been developed specifically for the analysis of 6-acetylmorphine (6-AM) with morphine and codeine because all three drugs are often present after heroin use. Assays of morphine and codeine by GC-MS are capable of high sensitivity, specificity, and selectivity. GCMS is superior to other analytical methods which provide important diagnostic value to study the drug abuse. The aim of this study was to establish methods and seek out 
more reliable identification and quantitation of morphine and codeine for detection addicts sample.

Currently, urine sampling has been extensively employed for the evaluation of drug consumption. Although through in saliva is another approach; the reliability of saliva analysis is limited by the fact that analyte levels, and even the availability of required sample volume, are again dependent on several physiological factors, nutrition and fluid intake, while the biological effects of the consumed illicit substance may also be a significant factor [10]. The identification of chronic consumers or the late verification of a single intake is feasible using hair as a matrix [11], but it is not suitable for the early verification of consumption. Urine is a preferable matrix for analytical purposes in comparison with saliva because of the minimal discomfort caused to sampled individuals, so it is widely available.

Sample preparation is a key step for the determination of drugs in biological samples. The simple and effective ethyl acetate extraction was employed in our work, and ethyl acetate was adopted because of its high extraction efficiency. Pyridine is a catalytic solvent for reactions with propionic anhydride. Propionic anhydride was chosen as the derivatization reagent because it exhibited better effect than acetic anhydride or trifluoroacetic acid anhydride, which could provide preferable stability, and the disadvantage of acetyl derivatives indistinguishable from morphine and the 6-AM can be avoided. Kushnir et al. [12] evaluated propionic anhydride, MBTFA, HFAA, and BSTFA for GC-MS analysis of 6AM. They concluded that propionic anhydride gave accurate, precise, and sensitive results while providing compatibility with other methods on the same GC-MS instrument. Residual derivatization reagent in the injector will react with drugs in other methods not intended for derivatization. The derivatization procedure accommodates the analysis of opioids commonly requiring GC-MS confirmation in urine. Difficulties were expected to arise due to a number of reasons. Concentrations of the analytes in the samples were expected to be smaller than the low end of the therapeutic range $(25 \mathrm{ng} / \mathrm{mL})$, which highlighted the importance of efforts aimed at increasing the sensitivity of detection. Validation of the analytical method also posed certain requirements. The relative standard deviation of the retention parameters of the target compound was required not to exceed 5\% relative standard deviation.

\section{Experimental}

2.1. Chemicals and Reagents. Morphine $[10 \mu \mathrm{g} / \mathrm{mL}$ in methanol] and codeine $[10 \mu \mathrm{g} / \mathrm{mL}$ in methanol] solutions were obtained from the Institute of Forensic Science under the Ministry of Justice (Shanghai, China). Sodium hydroxide (purity $>98.0 \%$ ) was purchased from Sigma-Aldrich Trading Co (Shanghai, P.R., China), and ethyl acetate (purity $>98.0 \%$ ) was purchased from Siyou Chemical Reagent Co., Ltd (Tianjin, China), and propionic acid anhydride (purity >98.0\%) was purchased from Sinopharm Chemical Reagent Co., Ltd (Beijing, China). Pyridine was from Shenbo Chemical Co., Ltd (Shanghai, China). While methanol was obtained from Siyou Chemical Reagent Co., Ltd (Tianjin, China). Ultrapure water was prepared by a Milli-Q purification system from Millipore (Bedford, USA). All other chemicals were analytical pure and used without further purification.

2.2. Instrumentation and Conditions. Analysis was performed on an Agilent 6890N gas chromatograph (GC) coupled with an Agilent 5975B mass spectrometer (MS, Agilent Technologies, Wilmington, DE, USA). Samples were injected using an Agilent autosampler unit.

The capillary column used was a HP-1MS [30 $\mathrm{m} \times$ $0.25 \mathrm{~mm}, 0.25 \mu \mathrm{m}]$. Helium was the carrier gas at a flow rate of $1.0 \mathrm{~mL} / \mathrm{min}$. The temperature program was: initial temperature, $100^{\circ} \mathrm{C}$ for $1.5 \mathrm{~min}$; ramp at $25^{\circ} \mathrm{C} / \mathrm{min}$ to $280^{\circ} \mathrm{C}$ and held for $15 \mathrm{~min}$; injection temperature, $250^{\circ} \mathrm{C}$; and transfer line, $280^{\circ} \mathrm{C}$. Sample injection volume was $1 \mu \mathrm{L}$. Splitless injection mode was used. Electron impact ionization was performed at $70 \mathrm{eV}$ energy and at a $230^{\circ} \mathrm{C}$ ion source temperature. The quadrupole temperature was $150^{\circ} \mathrm{C}$. The MS was operated in single ion monitoring (SIM) mode. SIM mode was applied to quantify analyzes using target ions at $m / z 341,397$, and 268 for morphine propionyl compound and $m / z 229,355$, and 282 for codeine propionyl compound (Figure 1).

2.3. Sample Preparation. The primary standard stock solutions of morphine $(100 \mu \mathrm{g} / \mathrm{mL})$ and codeine $(100 \mu \mathrm{g} / \mathrm{mL})$ were separately prepared in $10 \mathrm{~mL}$ volumetric flasks with urine; $10 \% \mathrm{NaOH}$ was added dropwise until $\mathrm{pH}$ 9.0-9.2 was reached, and $1.0 \mathrm{~mL}$ of borax buffer solution was added. To this, $3 \mathrm{~mL}$ of extraction solvent (ethyl acetate) was added and vortex-mixed on a vortexer for $2.0 \mathrm{~min}$, followed by centrifugation at $3000 \mathrm{r} / \mathrm{min}$ for $5 \mathrm{~min}$. The supernatant organic layer was transferred into a $5 \mathrm{~mL}$ glass test tube and dried under air stream at $60^{\circ} \mathrm{C}$. The dried residue was reconstituted in $50 \mu \mathrm{L}$ of propionic anhydride and $20 \mu \mathrm{L}$ of pyridine. All reagents were vortex-mixed, then heating for $3 \mathrm{~min}$ at $80^{\circ} \mathrm{C}$ and dried under air stream at $60^{\circ} \mathrm{C}$. The dried residue was reconstituted in $50 \mu \mathrm{L}$ of methanol, and $1 \mu \mathrm{L}$ of this solution was injected into GC-MS.

2.4. Method Validation. Specificity was determined by analysis of blank urine, without addition of morphine and codeine to determine possible interference with these compounds.

To evaluate the linearity, the calibration curves were generated using the analyte peak area by linear regression on three consecutive days. The LLOQ was estimated in the process of calibration curve construction and was defined as the lowest concentration for which precision (RSD) was better than $20 \%$.

QC samples at three concentration levels (50, 200, and $1600 \mathrm{ng} / \mathrm{mL}$ for morphine and codeine) were analyzed to assess the accuracy and precision of the method. Again, the assays were performed on three separate days, and on each day six replicates of the QC samples at each concentration level were analyzed. The assay accuracy was calculated as relative error. The assay precision for each QC level was determined as the relative standard deviation (RSD) of the measured concentrations. The intra- and interday precisions were required to be below $15 \%$, and the accuracy was required to be within $\pm 15 \%$. 


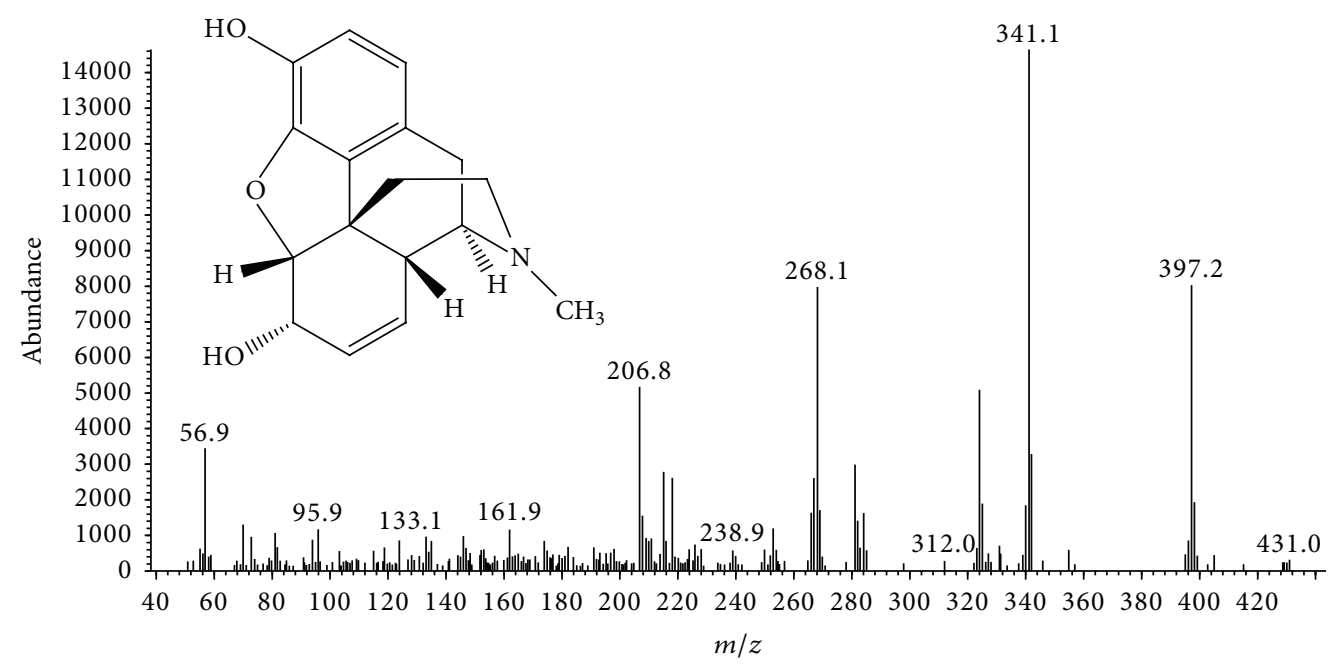

(a)

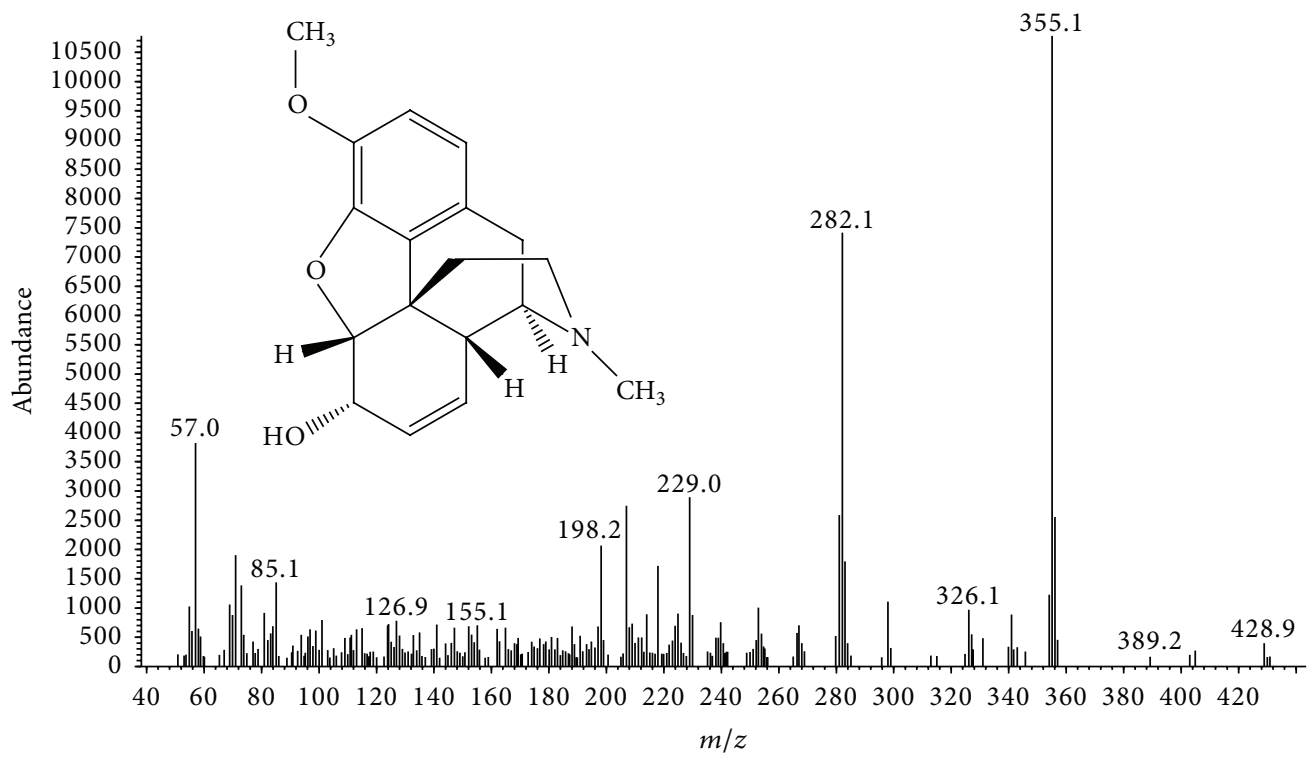

(b)

FIGURE 1: Mass spectra of morphine (a) and codeine (b) in SIM mode with EI (+) source.

Stability in urine was assessed in the autosampler at room temperature for $12 \mathrm{~h}$. The effect of three freeze-thaw cycles was also investigated.

\section{Results and Discussion}

3.1. Selectivity and Linearity. Figure 2 shows the typical chromatograms of a blank urine sample spiked with morphine and codeine. No interfering endogenous substances were observed at the retention times of the morphine and codeine.

Calibration curves for morphine and codeine were generated by linear regression of peak area ratios against concentrations, respectively. The regression equation for the calibration plot were $Y=2270.9 C+202.3$ with $r=0.9974$ for morphine, and $Y=3099.0 C+31625.7$ with $r=0.9958$ for codeine ( $Y$ is the peak area of analyte, and $C$ is the concentration of analyte in human urine), and concentrations are in the range $25-2000 \mathrm{ng} / \mathrm{mL}$ for morphine and codeine, respectively.

The LLOQ for morphine in human urine was $25 \mathrm{ng} / \mathrm{mL}$ and the precision and accuracy at LLOQ were $10.5 \%$ and $87.6 \%$, respectively. The LLOQ for codeine in human urine was $25 \mathrm{ng} / \mathrm{mL}$ and the precision and accuracy at LLOQ were $13.8 \%$ and $88.9 \%$, respectively.

3.2. Precision, Accuracy, and Extraction Recovery. The precision of the method was determined by calculating RSD for QCs at three concentration levels over three validation days. Intraday precision was $12 \%$ or less and the interday precision was $13 \%$ or less at each QC level. The accuracy of the method ranged from $87.2 \%$ to $99.7 \%$ at each QC level. Assay performance data are presented in Table 1. The aforementioned results demonstrate that the values are within the 


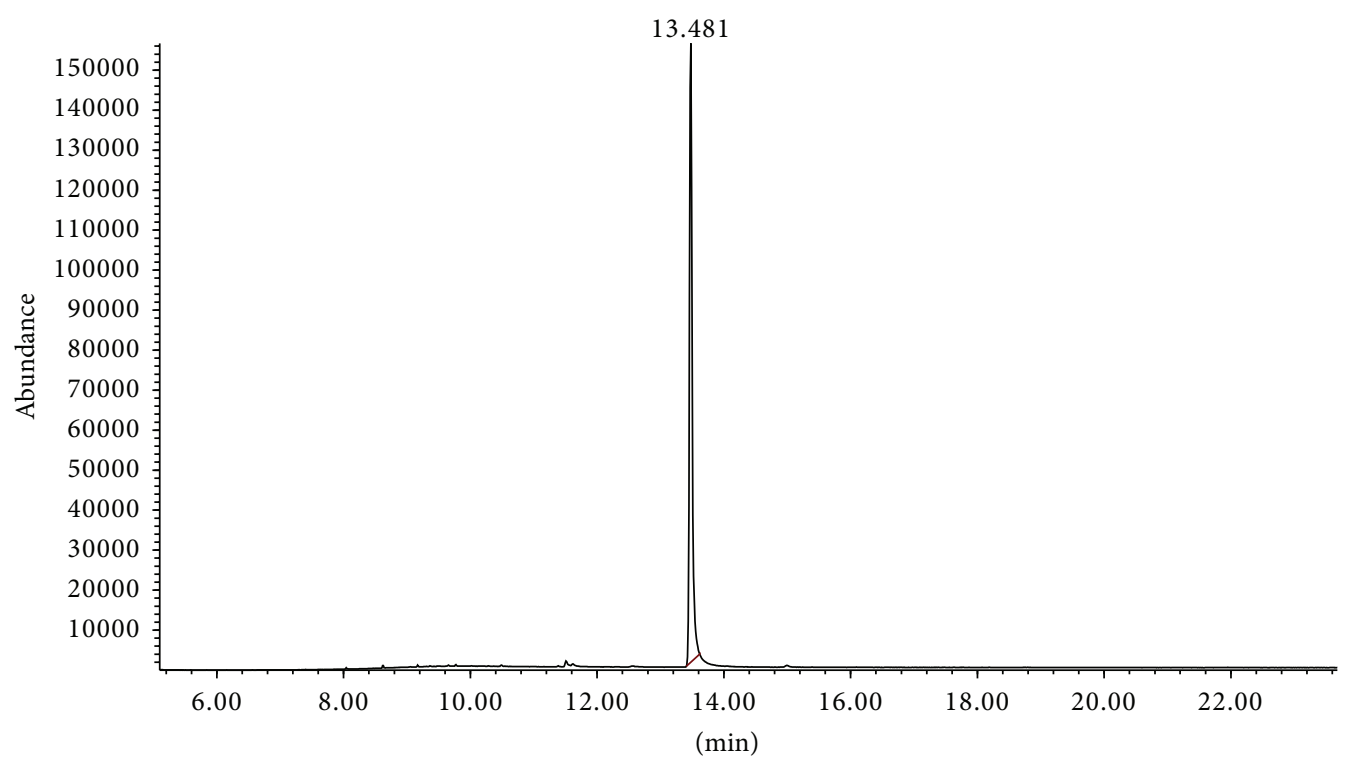

(a)

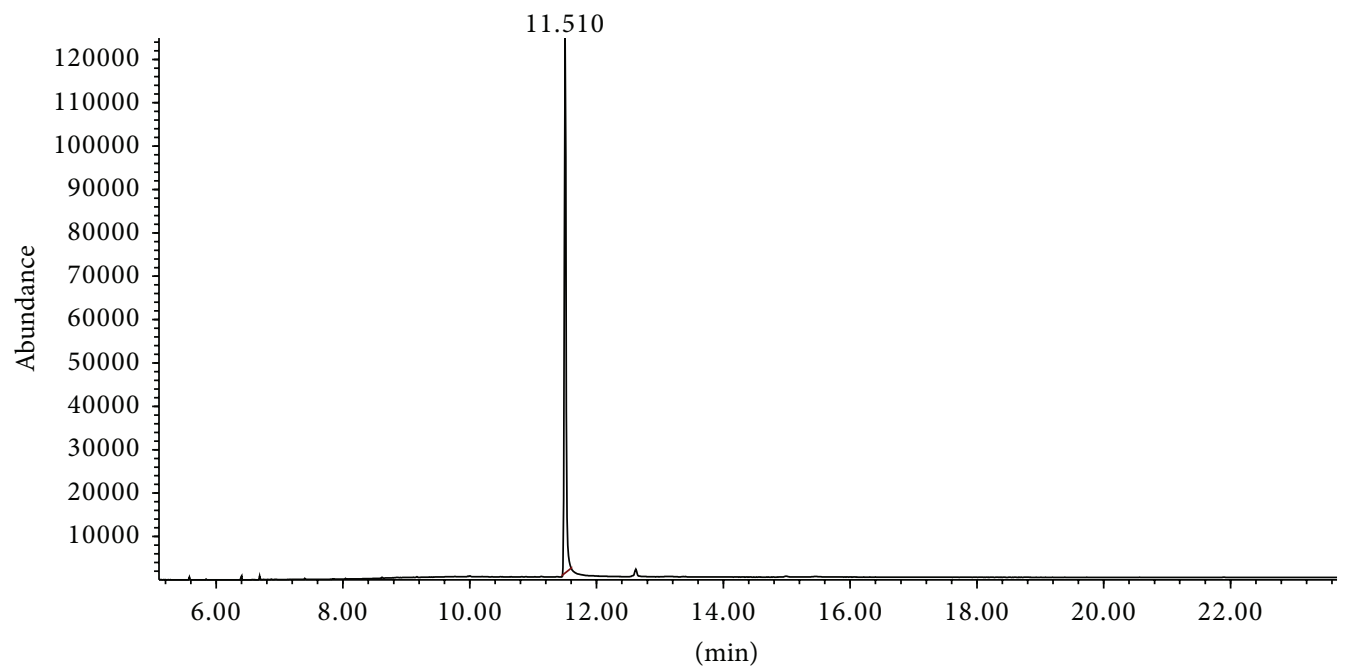

(b)

FIGURE 2: Chromatograph of urine sample containing $1600 \mathrm{ng} / \mathrm{mL}$ morphine (a) and codeine (b) processed through the procedure.

TABLE 1: The results of precision, accuracy, and recovery studies for morphine and codeine in human urine $(n=6)$.

\begin{tabular}{|c|c|c|c|c|c|c|}
\hline \multirow{2}{*}{ Compound } & \multirow{2}{*}{$\begin{array}{c}\text { Concentration } \\
(\mathrm{ng} / \mathrm{mL})\end{array}$} & \multicolumn{2}{|c|}{ RSD (\%) } & \multicolumn{2}{|c|}{$\mathrm{RE}(\%)$} & \multirow{2}{*}{ Recovery (\%) } \\
\hline & & Intraday & Interday & Intraday & Interday & \\
\hline \multirow{3}{*}{ Morphine } & 50 & 4.3 & 8.2 & -0.3 & -6.5 & 86.1 \\
\hline & 200 & 4.4 & 7.4 & -5.2 & -10.1 & 75.5 \\
\hline & 1600 & 5.3 & 9.3 & -6.9 & 5.7 & 80.2 \\
\hline \multirow{3}{*}{ Codeine } & 50 & 10.5 & 13.0 & 8.5 & -7.3 & 78.9 \\
\hline & 200 & 11.4 & 9.8 & -3.9 & -12.8 & 79.7 \\
\hline & 1600 & 5.2 & 12.9 & -9.9 & -8.2 & 86.8 \\
\hline
\end{tabular}


TABLE 2: Summary of stability of morphine and codeine under various storage conditions $(n=3)$.

\begin{tabular}{|c|c|c|c|c|}
\hline Compound & Condition & $\begin{array}{c}\text { Concentration }(\mathrm{ng} / \mathrm{mL}) \\
\text { Added }\end{array}$ & $\begin{array}{l}\text { RSD } \\
(\%)\end{array}$ & $\begin{array}{l}\mathrm{RE} \\
(\%) \\
\end{array}$ \\
\hline \multirow{6}{*}{ Morphine } & \multirow{3}{*}{ Three freeze-thaw cycles } & 50 & 2.5 & -10.1 \\
\hline & & 200 & 1.4 & -8.9 \\
\hline & & 1600 & 4.3 & -12.5 \\
\hline & \multirow{3}{*}{ Autosampler ambient $12 \mathrm{~h}$} & 50 & 2.1 & -10.5 \\
\hline & & 200 & 1.3 & -6.2 \\
\hline & & 1600 & 3.5 & -9.2 \\
\hline \multirow{6}{*}{ Codeine } & \multirow{3}{*}{ Three freeze-thaw cycles } & 50 & 3.2 & -8.9 \\
\hline & & 200 & 3.3 & -11.2 \\
\hline & & 1600 & 3.0 & -14.1 \\
\hline & \multirow{3}{*}{ Autosampler ambient $12 \mathrm{~h}$} & 50 & 3.3 & -11.1 \\
\hline & & 200 & 3.2 & -12.9 \\
\hline & & 1600 & 3.3 & -14.4 \\
\hline
\end{tabular}

acceptable range and the method is accurate and precise. The recovery of morphine and codeine was evaluated by comparing peak area ratios of extracted QC samples with those of reference QC solutions reconstituted in blank urine extracts. Mean recoveries of morphine and codeine were better than $75.5 \%$.

3.3. Stability. All the stability studies of morphine and codeine in human urine were conducted at three concentration levels $(50,200$, and $1600 \mathrm{ng} / \mathrm{mL}$ for morphine and codeine) with three replicates for each concentration. The stability results showed that morphine and codeine in human urine were stable during three freeze-thaw cycles. Stability of morphine and codeine extracts in the sample solvent on autosampler was also observed over a $12 \mathrm{~h}$ period. The results of stability experiments are listed in Table 2.

\section{Conclusions}

A stable, selective, and sensitive GC-MS method has been developed for the simultaneous determination of codeine and its metabolite morphine in human urine. This developed method with derivatization for sample preparation was successfully applied for the determination of morphine and codeine in human urine for methodological study.

\section{Conflict of Interests}

The authors declare that they have no conflict of interests.

\section{Acknowledgments}

This work was supported by the fund of the Youth Talent Program Foundation of The First Affiliated Hospital of Wenzhou Medical College (qnyc010). The authors thank Youting Zhang for valuable discussion and assistance with the modification. Furthhermore, the authors acknowledge the editors and the anonymous reviewers for their insightful suggestions on this work.

\section{References}

[1] M. Matyus, G. Kocsis, O. Boldis et al., "Determination of morphine and codeine in serum after poppy seed consumption using gas chromatography-mass spectrometry," Acta Chromatographica, vol. 24, pp. 351-365, 2012.

[2] J. Rodríguez, G. Castañeda, A. M. Contento, and L. Muñoz, "Direct and fast determination of paclitaxel, morphine and codeine in urine by micellar electrokinetic chromatography," Journal of Chromatography A, vol. 1231, pp. 66-72, 2012.

[3] L. Kovatsi, K. Rentifis, D. Giannakis, S. Njau, and V. Samanidou, "Disposable pipette extraction for gas chromatographic determination of codeine, morphine, and 6-monoacetylmorphine in vitreous humor," Journal of Separation Science, vol. 34, no. 14, pp. 1716-1721, 2011.

[4] T. Deim, C. Akay, K. Büyükafşar, and C. Cevherolu, "Simultaneous determination of codeine and ethyl morphine HCL in tablet formulations using LC," Journal of Pharmaceutical and Biomedical Analysis, vol. 26, no. 1, pp. 15-21, 2001.

[5] J.-O. Svensson, M. Andersson, E. Gustavsson, and O. Beck, "Electrospray LC-MS method with solid-phase extraction for accurate determination of morphine-, codeine-, and ethylmorphine-glucuronides and 6-acetylmorphine in urine," Journal of Analytical Toxicology, vol. 31, no. 2, pp. 81-86, 2007.

[6] R. Coles, M. M. Kushnir, G. J. Nelson, G. A. McMillin, and F. M. Urry, "Simultaneous determination of codeine, morphine, hydrocodone, hydromorphone, oxycodone, and 6acetylmorphine in urine, serum, plasma, whole blood, and meconium by LC-MS-MS," Journal of Analytical Toxicology, vol. 31, no. 1, pp. 1-14, 2007.

[7] Q. Liao, Y. Deng, Z. Xie, B. Pan, and L. Zhang, "Rapid simultaneous determination of codeine and morphine in plasma using LC-ESI-MS/MS: application to a clinical pharmacokinetic study," Journal of Separation Science, vol. 32, no. 2, pp. 202-211, 2009.

[8] D.-K. Huang, C. Liu, M.-K. Huang, and C.-S. Chien, "Simultaneous determination of morphine, codeine, 6-acetylmorphine, cocaine and benzoylecgonine in hair by liquid chromatography/electrospray ionization tandem mass spectrometry," Rapid Communications in Mass Spectrometry, vol. 23, no. 7, pp. 957962, 2009. 
[9] R. Meatherall, "GC-MS confirmation of codeine, morphine, 6-acetylmorphine, hydrocodone, hydromorphone, oxycodone, and oxymorphone in urine," Journal of Analytical Toxicology, vol. 23, no. 3, pp. 177-186, 1999.

[10] O. H. Drummer, "Drug testing in oral fluid," Clinical Biochemist Reviews, vol. 27, pp. 147-159, 2006.

[11] L. Tsanaclis and J. F. C. Wicks, "Patterns in drug use in the United Kingdom as revealed through analysis of hair in a large population sample," Forensic Science International, vol. 170, no. 2-3, pp. 121-128, 2007.

[12] M. M. Kushnir et al., "Comparison of four derivatizing reagents for 6-acetylmorphine GC-MS analysis," Journal of Analytical Toxicology, vol. 23, pp. 262-269, 1999. 

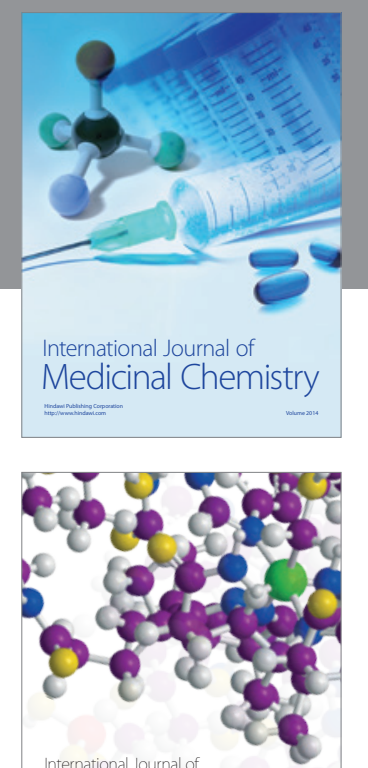

\section{Carbohydrate} Chemistry

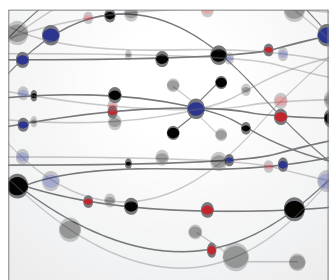

The Scientific World Journal
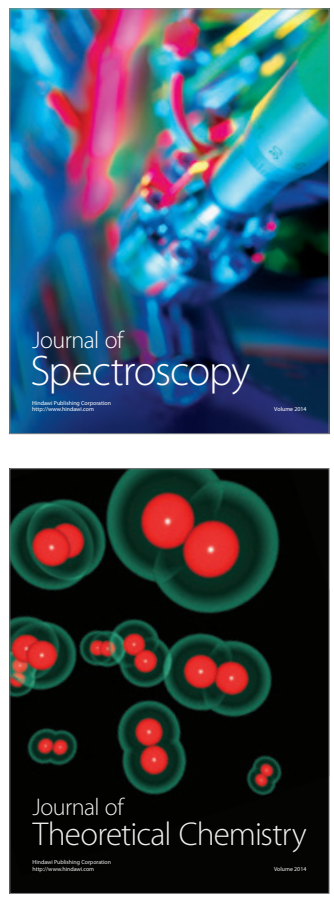
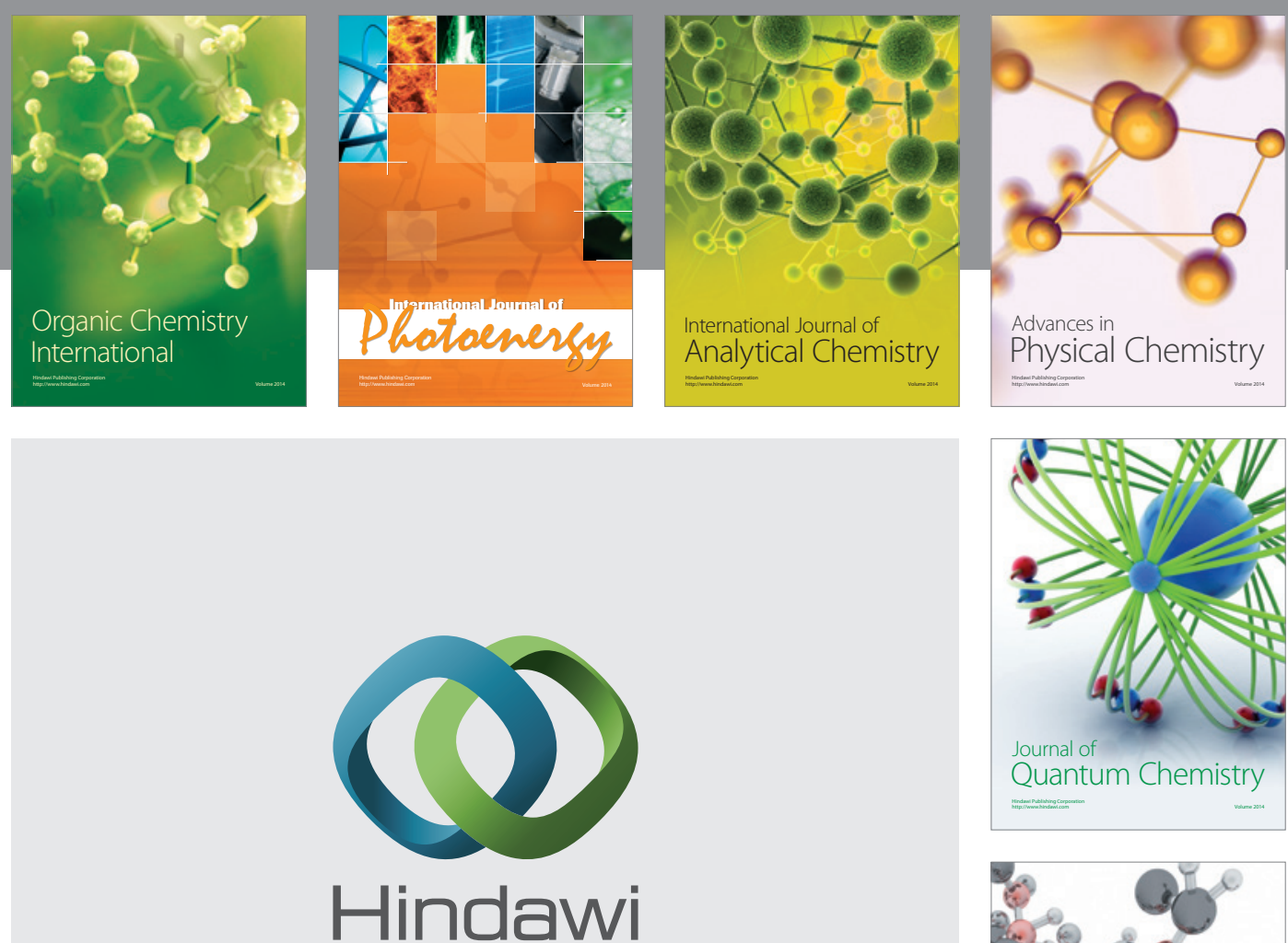

Submit your manuscripts at

http://www.hindawi.com

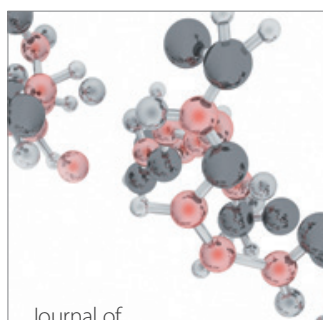

Analytical Methods

in Chemistry

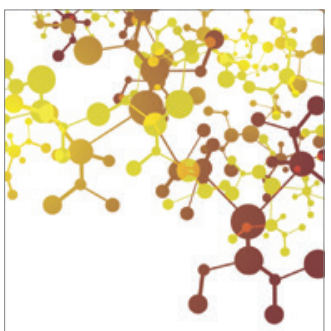

Journal of

Applied Chemistry

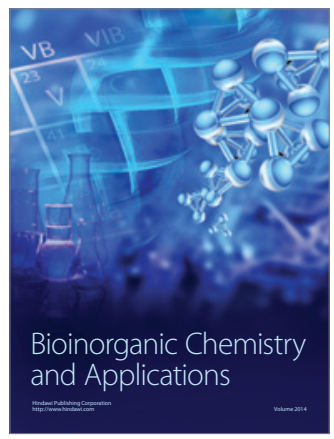

Inorganic Chemistry
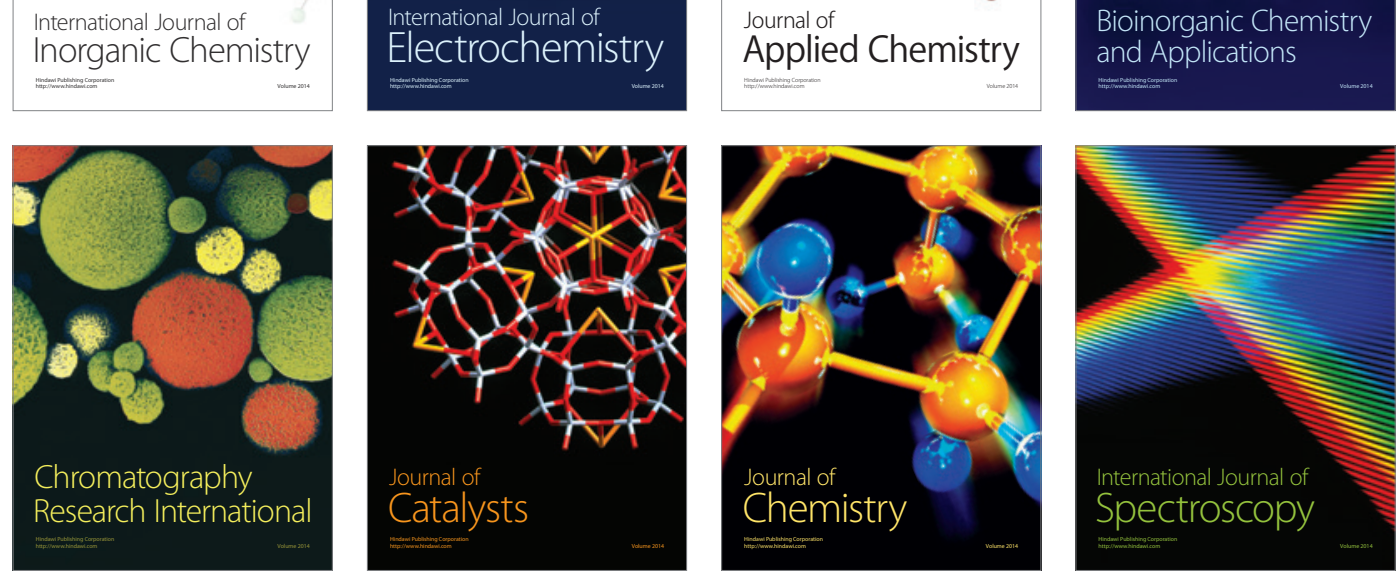